\title{
Hohlraum Designs for High Velocity Implosions on NIF
}

N. B. Meezan, D. G. Hicks, D. A. Callahan, R. E. Olson, M. S.

Schneider, C. A. Thomas, H. F. Robey, P. M. Celliers, J. K. Kline, S. N. Dixit, P. A. Michel, O. S. Jones, D. S. Clark, J. E. Ralph, T. Doeppner, A. J. MacKinnon, S. W. Haan, O. L. Landen, S. H. Glenzer, L. J. Suter, M. J. Edwards, B. J. Macgowan, J. D. Lindl, L. J. Atherton

October 28, 2011

7th International Conference on Inertial Fusion Sciences and Applications

Bordeaux, France

September 12, 2011 through September 16, 2011 
This document was prepared as an account of work sponsored by an agency of the United States government. Neither the United States government nor Lawrence Livermore National Security, LLC, nor any of their employees makes any warranty, expressed or implied, or assumes any legal liability or responsibility for the accuracy, completeness, or usefulness of any information, apparatus, product, or process disclosed, or represents that its use would not infringe privately owned rights. Reference herein to any specific commercial product, process, or service by trade name, trademark, manufacturer, or otherwise does not necessarily constitute or imply its endorsement, recommendation, or favoring by the United States government or Lawrence Livermore National Security, LLC. The views and opinions of authors expressed herein do not necessarily state or reflect those of the United States government or Lawrence Livermore National Security, LLC, and shall not be used for advertising or product endorsement purposes. 


\title{
Hohlraum Designs for High Velocity Implosions on NIF
}

\author{
Nathan B. Meezan ${ }^{1, a}$, Damien G. Hicks ${ }^{1}$, Debra A. Callahan ${ }^{1}$, Richard E. Olson ${ }^{2}$, Marilyn S. \\ Schenider $^{1}$, Cliff A. Thomas ${ }^{1}$, Harry F. Robey, Peter M. Celliers, John L. Kline ${ }^{3}$, Shamasundar N. \\ Dixit $^{1}$, Pierre A. Michel ${ }^{1}$, Ogden S. Jones ${ }^{1}$, Daniel S. Clark ${ }^{1}$, Joseph E. Ralph ${ }^{1}$, Tilo Döppner ${ }^{1}$, \\ Andrew J. MacKinnon ${ }^{1}$, Steven W. Haan ${ }^{1}$, Otto L. Landen ${ }^{1}$, Siegfried H. Glenzer ${ }^{1}$, Laurence J. \\ Suter $^{1}$, Michael J. Edwards ${ }^{1}$, Brian J. MacGowan ${ }^{1}$, John D. Lindl ${ }^{1}$, and Lawrence J. Atherton ${ }^{1}$ \\ 1 Lawrence Livermore National Laboratory, Livermore, CA, U.S.A. \\ 2 Sandia National Laboratories, Albuquerque, NM, U.S.A. \\ 3 Los Alamos National Laboratory, Los Alamos, NM, U.S.A.
}

\begin{abstract}
In this paper, we compare experimental shock and capsule trajectories to design calculations using the radiation-hydrodynamics code HYDRA. The measured trajectories from surrogate ignition targets are consistent with reducing the $\mathrm{x}$-ray flux on the capsule by about $85 \%$. A new method of extracting the radiation temperature as seen by the capsule from $x$-ray intensity and image data shows that about half of the apparent $15 \%$ flux deficit in the data with respect to the simulations can be explained by HYDRA overestimating the $\mathrm{x}$-ray flux on the capsule.
\end{abstract}

\section{Introduction}

The National Ignition Campaign (NIC) point-design target is designed to reach a peak fuel-layer velocity of $370 \mathrm{~km} / \mathrm{s}$ by ablating $90 \%$ of its plastic $(\mathrm{CH})$ ablator. The 192-beam National Ignition Facility laser [1] drives a gold hohlraum [Fig. 1 (a)] to a radiation temperature $\left(T_{R A D}\right)$ of $300 \mathrm{eV}$ with a 20 nslong, $420 \mathrm{TW}, 1.3 \mathrm{MJ}$ laser pulse. The hohlraum x-rays couple to the $\mathrm{CH}$ ablator [Fig. 1 (b)] in order to apply the required pressure to the outside of the capsule. In this paper, we compare experimental measurements of the hohlraum $T_{R A D}$ and the implosion trajectory with design calculations using the code HYDRA [2]. The measured radial positions of the leading shock wave and the unablated shell are consistent with simulations in which the x-ray flux on the capsule is artificially reduced by $85 \%$. We describe a new method of inferring the $T_{R A D}$ seen by the capsule from time-dependent x-ray intensity data and static X-ray images. This analysis shows that HYDRA overestimates the X-ray flux incident on the capsule by $\approx 8 \%$.

\section{Experiments and comparison to simulations}

HYDRA is a 3-D radiation-hydrodynamics code that handles all of the physics needed to model ICF experiments [2]. The 2-D integrated (hohlraum + capsule) simulations described in this paper use the "high-flux model"-electron thermal conduction with a flux-limiter $f=0.15$ and the DCA non-LTE atomic physics model [7]. The input laser sources are adjusted to account for backscattered light and for cross-beam transfer occurring in the hohlraum plasma $[8,9]$. In some simulations, the laser source is further degraded to match experimental shock-front and ablator data.

We assess the ablation pressure history on the capsule by comparing measured trajectories of the leading shock-wave (from shock-timing "keyhole" targets) and the unablated shell (from back-lit radiography "convergent ablator" targets) with simulated quantities. The surrogate tuning experiments,

\footnotetext{
a e-mail: meezan1@llnl.gov
} 

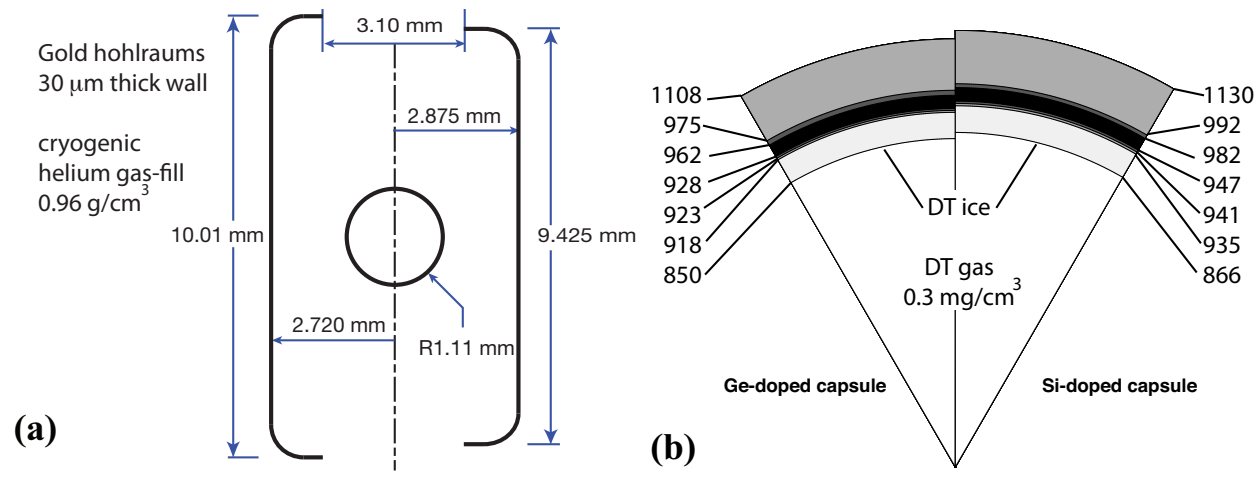

Fig. 1. (a). Ignition hohlraum designs. (b). Ignition capsule designs. The capsule on the left has layers (from inside to out) of DT ice, clean $\mathrm{CH}, 0.5 \% \mathrm{Ge}$-doped $\mathrm{CH}, 1 \% \mathrm{Ge}, 0.5 \% \mathrm{Ge}$, and clean $\mathrm{CH}$. The capsule on the right has layers of DT ice, clean $\mathrm{CH}, 1 \%$ Si-doped $\mathrm{CH}, 2 \% \mathrm{Si}, 1 \% \mathrm{Si}$, and clean $\mathrm{CH}$.
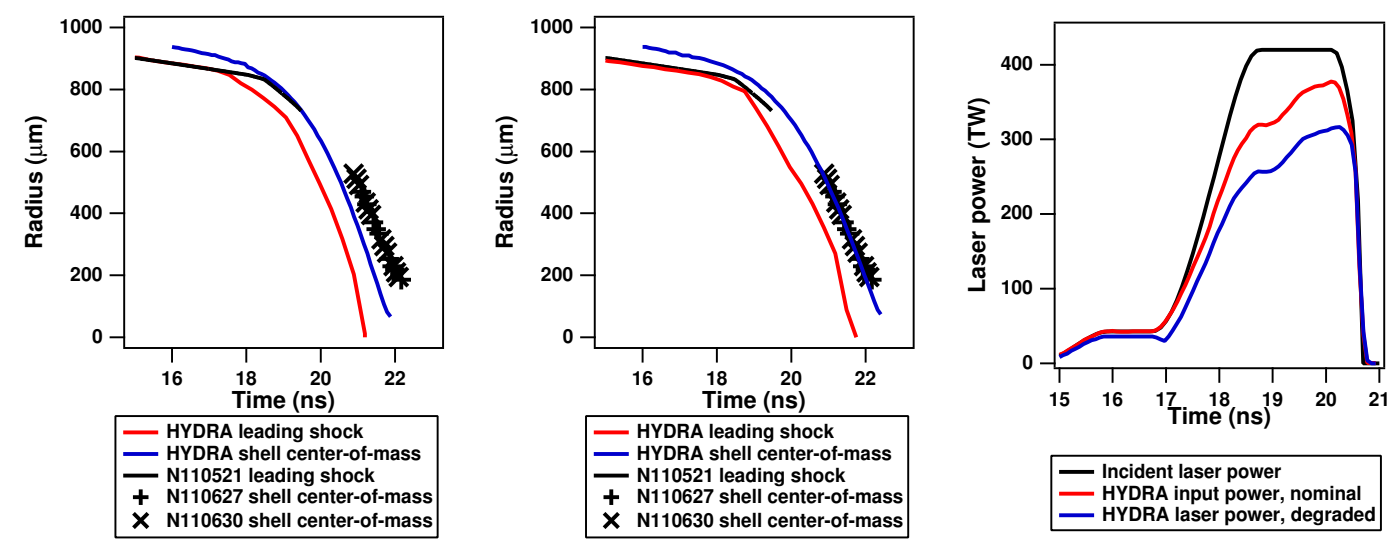

Fig. 2. Measured shock-wave and unablated shell trajectories compared with HYDRA simulations using nominal (a.) and degraded (b.) laser pulses. The incident pulse, nominal pulse, and degraded pulse are shown in (c.).

as well as the standard NIC laser and diagnostic setup, are described in other papers in these proceedings and in previous papers [3-6]. In Figs. 2(a) and 2(b), we show the trajectory of the leading shock-wave measured in liquid deuterium in a keyhole target on NIF shot N110521 (May 21, 2011). This is plotted with the radial position of the center-of-mass of the unablated $\mathrm{CH}$ shell, measured with back-lit radiography on the convergent ablator target shots N110627 and N110630. These data are representative of the shock and shell trajectories during shots using Si-doped ignition capsules with cryogenic DT layers.

We compare the data to the leading shock trajectory and center-of-mass radius from integrated HYDRA simulations of a Si-doped capsule with a cryogenic DT layer. Figure 2(a) shows a simulation with the nominal laser pulse, equal to the incident laser pulse minus the measured backscatter[8][red in Fig. 2(c)]. The time at which the 4th shock over-takes the third is earlier than in the data by $\approx 200$ ps. The unablated shell position is correspondingly early. Figure 2(b) shows the same simulation with the laser power degraded by an additional $15 \%$ [blue in Fig. 2(c)]. In this simulation, both the shock front and shell trajectories agree reasonably well with the data. Note that the $15 \%$ degradation is approximate: while "bang time" data from many NIC implosions are consistent with $\approx 85 \%$ of the HYDRA flux, some data are better fit by a factor of 90-95\% (c.f., Olson et al. in these proceedings). 


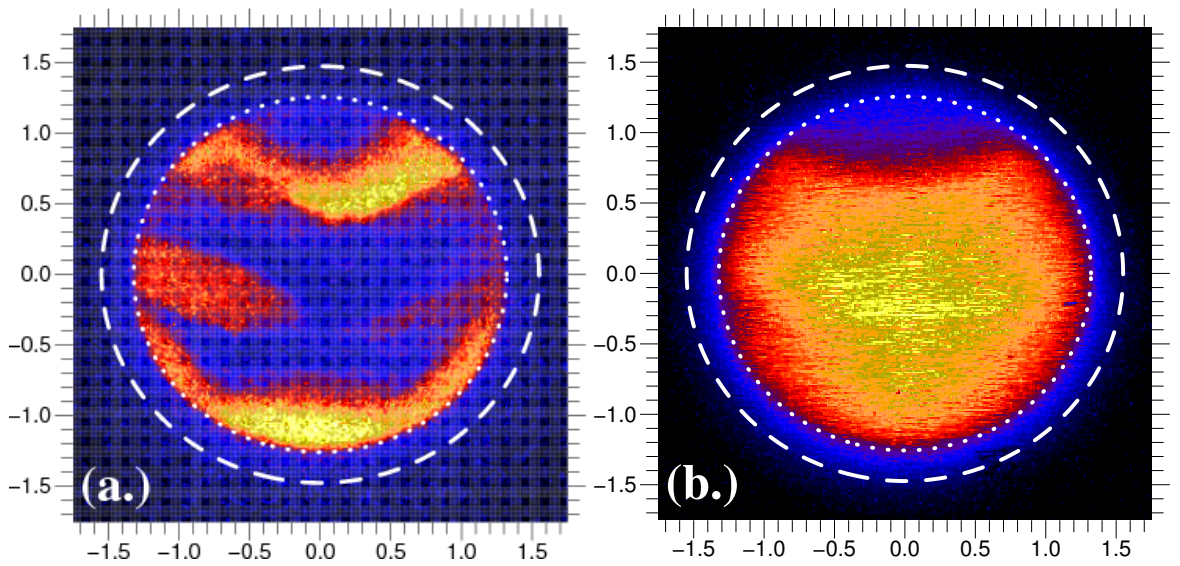

Fig. 3. Measured SXI images in the $3-5 \mathrm{keV}$ filtered channel (a.) and $870 \mathrm{eV}$ monochromatic mirror channel (b) for the symcap shot N110527. In both images, the dashed line is the original size of the LEH, $R_{L E H}=1.55 \mathrm{~mm}$. The dotted line is the "clear area" determined by the full-width at half-maximum of the azimuthal average of the 3-5 keV filtered image, (a). The halo correction is the fraction of the emission originating outside of the dotted line in the $870 \mathrm{eV}$ image, (b).

\section{Hohlraum radiation temperature}

The simulation described above was adjusted to match the data by reducing the net laser power delivered to the hohlraum; however, we cannot discern the source of the ablation pressure deficit from these data alone. The capsule implosion trajectory is an integral measure of several physical processes: the generation of $\mathrm{x}$-rays in the hohlraum, the transport of $\mathrm{x}$-rays to the capsule, the coupling of $\mathrm{x}$-rays to the capsule ablation front, and the response of the capsule to the ablation pressure. We attempt to isolate hohlraum physics by extracting the radiation temperature $T_{R A D}$ seen by the capsule. We can calculate the brightness temperature of the hohlraum from the measured radiant intensity $\Phi[\mathrm{GW} / \mathrm{sr}]$ of the hohlraum LEH and the effective source-size $A_{L E H}$,

$$
T_{R A D}=\left(\frac{\pi I_{a v}}{\sigma}\right)^{1 / 4}=\left(\frac{\pi \Phi}{\sigma A_{L E H} \cos \theta}\right)^{1 / 4}
$$

Here, $I_{a v}$ is the total average X-ray intensity $\left[\mathrm{GW} / \mathrm{sr} / \mathrm{cm}^{2}\right]$ and $\sigma$ is the Stefan-Boltzmann constant. The radiant intensity $\Phi$ is measured by the DANTE diagnostic, an 18 channel array of filtered x-ray diodes, at an angle $\theta=37.5^{\circ}$ [10]. DANTE data from the symmetry-capsule target shot N110527 are compared with a HYDRA prediction for that shot in Fig. 4(a).

The source-size $A_{L E H}$ is found from the two static X-ray imagers (SXI's)[11], time-integrated Xray pinhole cameras that view the LEH at $\theta=18^{\circ}$ and $\theta=19^{\circ}$ (Fig. 3). The broadband channel ( $3 \mathrm{keV}<h v<5 \mathrm{keV}$ ) image delineates the dense, absorbing part of the LEH from the "clear area," where X-rays leaving the hohlraum are not significantly attenuated before reaching the DANTE. This image identifies $A_{L E H}$ in Eq. 1. The monochromatic channel ( $h v \approx 870 \mathrm{eV}$, near the peak of the blackbody spectrum for $T=300 \mathrm{eV}$ ) shows x-rays that originate from within the clear aperture as well as a "halo" of x-rays either emitted from or attenuated by the gold LEH plasma. Only x-rays from the clear area $A_{L E H}$ should be counted when calculating $T_{R A D}$. This image identifies the "halo correction" factor $f$, the fraction of x-rays outside the clear area.

Simulated data from HYDRA show that the time-integrated SXI images are characteristic of the clear-area and halo at the time of peak intensity (as measured in DANTE). We approximate the timedependent clear area $A_{L E H}$ and halo-factor $f$ as varying linearly between their initial values at $t=0$ and the SXI data at the time of peak intensity, $t=t_{\text {peak }}$,

$$
A_{L E H}(t)=\pi R_{L E H}^{2}\left(1-\frac{t}{t_{\text {peak }}}\right)+A_{L E H, S X I}\left(\frac{t}{t_{\text {peak }}}\right) ; \quad f(t)=f_{S X I}\left(\frac{t}{t_{\text {peak }}}\right)
$$




\section{EPJ Web of Conferences}

Since the capsule sees both the hohlraum wall and the LEH, reduce the flux seen by the capsule by the area subtended by the LEH's. The final expression for $T_{R A D}(t)$ is given by

$$
T_{R A D}(t)=\left(\frac{\pi[1-f(t)] \Phi(t)}{\sigma A_{L E H}(t) \cos \theta} \frac{L}{\sqrt{R_{L E H}^{2}(t)+L^{2}}}\right)^{1 / 4} .
$$

Here, $L$ is the hohlraum half-length and the time-dependent LEH radius $R_{L E H}(t)=\sqrt{A_{L E H}(t) / \pi}$.
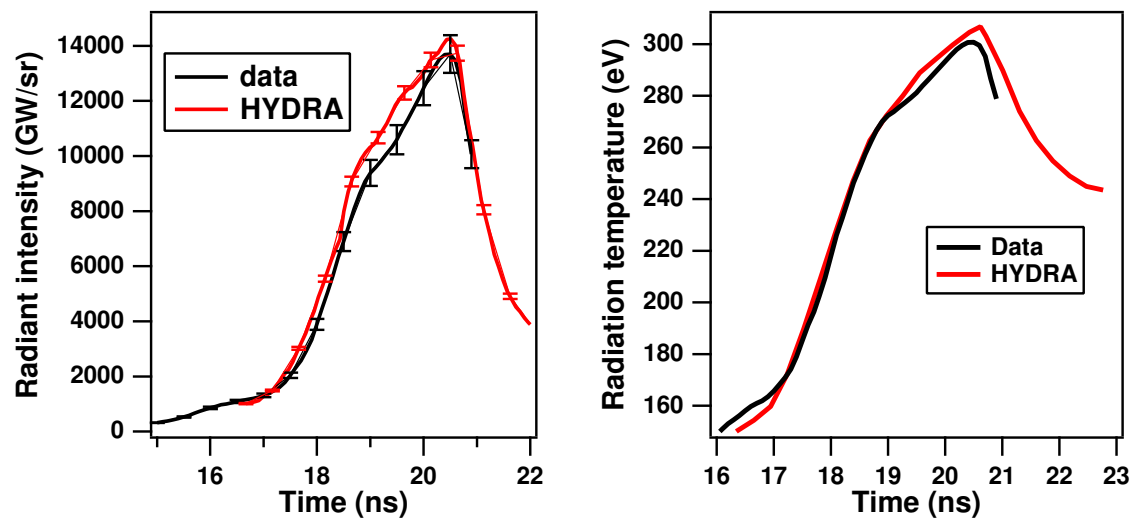

Fig. 4. (a). Comparison of measured (black) and HYDRA simulated DANTE radiant intensity for symcap shot N110527 (b). Comparison of the $T_{R A D}$ seen by the capsule determined by Eq. 3 from the DANTE and SXI diagnostics for symcap shot N110527 (black) to the $T_{R A D}$ seen by the capsule extracted from a HYDRA simulation by ray-tracing

For most NIC hohlraum shots, the DANTE intensity $\Phi(t)$ from HYDRA agrees with the data to within the $\pm 5 \%$ error bars [Fig. 3(c)]. On the other hand, the clear-area predicted by HYDRA simulated $\mathrm{SXI}$ is $\approx 100 \mu \mathrm{m}$ smaller than the data. The halo-correction $f$ tends to be similar between simulations and data. Thus, the intensity measured in DANTE corresponds to a slightly lower $T_{R A D}$ in the data than in a HYDRA simulation. This is shown for N110527 in Fig. 3(b). For HYDRA, the peak $T_{R A D}=307$ $\mathrm{eV}$ compared to $301 \mathrm{eV}$ from the data, so the flux $\sigma T_{R A D}^{4}$ inferred from the data is $8 \%$ below the simulation. This is about half of the $15 \%$ degradation needed to bring the simulated shell and shock trajectories into agreement with the data (Fig. 2). The remaining deficit may be attributable to capsule physics uncertainties. We are currently applying this analysis method to other NIC hohlraum shots.

\section{References}

1. E. Moses, R. Boyd, B. Remington, C. Keane, and R. Al-Ayat, Phys. Plasmas 16, 041006 (2009).

2. M. M. Marinak, G. D. Kerbel, N. A. Gentile, O. Jones, D. Munro, S. Pollaine, T. R. Dittrich, and S. W. Haan, Phys. Plasmas 8, 2275 (2001).

3. O. L. Landen. M. J. Edwards, S. W. Haan et al., Phys. Plasmas 18, 051002 (2011).

4. H. F. Robey, T. R. Boehly, R. E. Olson et al., Phys. Plasmas 17, 012703 (2010).

5. D. G. Hicks. B. K. Spears, D. G. Braun et al., Phys. Plasmas 17, 102703 (2010).

6. N. B. Meezan, L. J. Atherton, D. A. Callahan et al., Phys. Plasmas 17, 056304 (2010).

7. M. D. Rosen, H. A. Scott, D. E. Hinkel et al., High Energy Density Phys. 7, 180 (2011).

8. R. P. J. Town. M. D. Rosen. P. A. Michel et al., Phys. Plasmas 18, 056302 (2011).

9. P. Michel, S. H. Glenzer, L. Divol et al., Phys. Plasmas 17, 056305 (2010).

10. E. L. Dewald, O. Landen, L. Suter, et al., Rev. Sci. Instrum. 75, 3759 (2004).

11. M. B. Schenider, O. S. Jones, N. B. Meezan et al., Rev. Sci. Instrum. 81, 10E538 (2010). 